\title{
GESTÃ O DA PRODUÇÃO E MAPEAMENTO DE PROCESSOS NA CARIMBU: ASSOCIAÇÃO ESPECIALIZADA NA CADEIA PRODUTIVA DO UMBU E DERIVADOS
}

\author{
Gabriel Mendes de Souza (UFCG) gabrielmendes384@gmail.com \\ Cledenilda Ferreira Rodrigues (UFCG) cledenilda@gmail.com \\ Filipe da Silva Marinho (UFCG) felipe_guarabira12@hotmail.com \\ Ana Mary da Silva (UFCG) aninha123@yahoo.com
}

\section{Resumo}

As associações agroindustriais possibilitam aos trabalhadores de uma cadeia produtiva de um determinado produto agrícola um caminho efetivo para participar do mercado em melhores condições de concorrência, atuando na transformação de uma matéria prima agrícola em um produto agroindustrial final. Este estudo de caso é voltado para o mapeamento de processos e gerenciamento de custos de produtos agroindustriais advindos da cadeia produtiva do umbu. $\mathrm{O}$ objetivo é melhorar o gerenciamento dos custos da produção, compreender os processos mediante o mapeamento, com o intuito de verificar falhas na gestão de produção e aumentar a lucratividade da associação. Assim, entende-se que os associados devem ser reorganizados em uma rotina, para atuarem na colheita durante a safra e no beneficiamento do umbu para tentar encontrar um equilíbrio entre oferta e demanda até obterem estrutura para operar em escala industrial. A utilização do tempo disponível ao processamento é primordial para conseguir atender a demanda, aumentando a produção e os lucros. Destarte, elaborou-se um plano de melhoria para a organização produtiva, reiterando a importância da aplicação dos conhecimentos técnicos da Engenharia de Produção.

Palavras-chave: Agroindústria; Custos; Produtos Agrícolas; Agronegócio.

\section{Introdução}

O profissional de engenharia de produção possui características multidisciplinares, sendo capaz de oferecer apoio a qualquer tipo de organização auxiliando nas mais diversas atividades. Assim, qualquer organização que busque otimizar seus processos de produção, como organizações que fabricam algum produto, organizações prestadoras de serviços, instituições públicas, instituições privadas, bancos de investimento e também o agronegócio, podem ter o auxílio do engenheiro de produção (Másculo,2006). 
Dentre esses setores, o do agronegócio, tem se mostrado nos últimos anos um dos setores mais importantes para economia Brasileira. De acordo com o Centro de Estudos Avançados em Economia Aplicada (CEPEA), entre 1996 e 2018 o agronegócio brasileiro representou uma parcela relevante do PIB (Produto interno Bruto) nacional com uma média de 24\%. Resultados obtidos devido à sua capacidade de expansão de produtividade e produção e de sua geração de oportunidades de empregos em diversas regiões (Castro, 2019).

Dentro do agronegócio, as associações rurais, possibilitam aos trabalhadores e pequenos proprietários um caminho efetivo para participar do mercado em melhores condições de concorrência. Com a cooperação formal entre os sócios afins, a produção e comercialização de bens e serviços tendem a ser bastante rentáveis, e pequenos produtores que antes teriam bastantes dificuldades para obter um bom desempenho econômico, têm na formação de associações um mecanismo que lhes garante um melhor desempenho para competir no mercado (MAPA,2016).

Para um melhor desempenho da associação rural, ou qualquer outra organização, a utilização de ferramentas como mapeamento dos processos se torna fundamental, pois permite a identificação dos principais passos e decisões em um fluxo de trabalho de rotina de forma visual. Além disso, pode-se obter o controle do fluxo de informações, documento e materiais envolvidos no processo e esclarece tarefas, decisões e ações que são necessárias em determinados pontos no tempo (BARBROW; HARTLINE, 2015).

Com o mapeamento dos processos, também é possível ter um melhor gerenciamento de custos da produção, que possibilitará numa melhor determinação do preço de venda, num melhor controle sobre as despesas, evitando, assim, prejuízos e permitindo a sobrevivência da organização em meio ao mercado (ZAHAIKEVITCH, 2012;).

Diante do exposto, o presente artigo desempenha-se através da revisão bibliográfica acerca do mapeamento de processos e gerenciamento de custos, atrelado ao estudo de caso na associação Carimbu, produtora de bens alimentícios da cadeia produtiva do umbu, localizada na cidade de Sumé na Paraíba, com o objetivo de melhorar o gerenciamento dos custos da produção, compreender os processos através do mapeamento, a fim de identificar falhas e aumentar os lucros da organização.

\section{Referencial teórico}




\subsection{Gestão por Processos}

De acordo com Araújo (2011), pode-se definir que a gestão de processos aborda o planejamento, a organização, controle e direção dos processos existentes dentro das organizações, pelo qual se caracteriza por se tratar de uma gestão mais específica com o intuito de buscar entender os seus processos, no enfoque de melhorar o seu desempenho e aprimorar os seus resultados.

Conforme Carvalho et al. (2005), é necessário que na gestão por processos haja uma interação significante de toda a equipe de trabalho, desde gestores até operadores. Resultando assim em uma maior satisfação no trabalho, redução de custos com retrabalho e desperdício de mão de obra, além do desenvolvimento de habilidades, pois com a coparticipação dos colaboradores é necessário o conhecimento aprofundado das atividades.

\subsection{Mapeamento de Processos}

Conforme Mareth; Alves; Borba (2009, p. 4), o mapeamento de processos "é uma ferramenta gerencial analítica e de comunicação que têm a intenção de ajudar a melhorar os processos existentes ou de implantar uma nova estrutura voltada para processos".

Para Orofino (2009), a realização do mapeamento de processos deve se iniciar a partir de uma visão sistêmica do processo para então a partir daí partir para uma visão mais específica, identificando assim as principais atividades e funções pertinentes ao processo, assim como os responsáveis pela execução de tais atividades.

Além de existir organogramas que definem e ilustram a estrutura das empresas é possível construir uma representação gráfica dos processos, mediante o mapeamento dos mesmos, este método aborda uma visão mais ampla do processo, com a identificação detalhada de suas etapas e então facilitando o entendimento dos fluxos de atividades realizadas discorrendo da melhor aplicação para possíveis melhorias (CURY, 2010).

\subsection{Gestão de Custos}


Segundo Dutra (1995), a competitividade provocada pela concorrência e a busca do crescimento sustentado, fizeram com que as organizações buscassem um gerenciamento mais efetivo dos custos. O exercício de apuração dos custos não deve ocorrer somente no tabelamento de preços ou em períodos de acirrada concorrência. Deve acontecer de modo contínuo, permitindo tomadas de decisões eficazes.

De acordo com Bertó e Beulke (2005), o cálculo dos custos do produto irá influenciar nas decisões dos preços dos produtos. Os gerentes devem monitorar os custos dos processos operacionais para manter um controle, fazendo com que a empresa utilize de forma eficiente esse recurso.

\subsection{Fluxograma}

De acordo com Oliveira (2013), o fluxograma se trata de uma representação gráfica que utiliza de diferentes formas geométricas representativas, apresenta a sequência de um trabalho de forma analítica, determinando as operações, os responsáveis e/ou unidades organizacionais envolvidas. Ainda aborda as várias etapas de processos, facilitando o entendimento, pontos de melhoria.

Chinelato Filho (1993) idealiza a respeita de definição e características de um fluxograma, que ele aborda de forma clara, objetiva e nítida as etapas com problemas e atividades desnecessárias, podendo, assim, propor medidas de melhoramento a respeito da utilização de recursos, a ocorrência do processo e a simplificação do trabalho. Auxilia também no processo de gerenciamento da organização.

\subsection{Extrativismos e sua importância para as comunidades}

Segundo Gama et. al., (2017), no Nordeste do Brasil, o extrativismo de Produtos Florestais Não Madeireiros (PFNM) constitui-se de uma atividade com importância e grande potencial na produção sustentável e geração de emprego e renda, principalmente para aquelas populações desprovida de alternativas produtivas mais viáveis, que procuram meios de se sustentarem e terem uma renda melhor.

De acordo com Souza (2003), o extrativismo vegetal é caracterizado pela utilização de um baixo investimento de capital e uso de tecnologias simplificadas pelo qual a mão de obra é a variável mais importante no extrativismo, transporte e transformação do produto. 


\section{Metodologia}

O propósito da pesquisa é descritivo; a abordagem é qualitativa; os métodos do trabalho consistem em entrevistas e pesquisa de campo. As técnicas utilizadas para a coleta dos dados na associação Carimbu foram: marcação de entrevista por meio de contato telefônico e explicação das metas da pesquisa; encaminhamento prévio do roteiro de entrevista; realização das entrevistas de forma presencial seguindo o roteiro anteriormente encaminhado; gravação de todas as observações da entrevistada com o uso de aparelhos celulares a fim de obter os dados da produção e a coleta de documentação como planilhas referentes aos custos , à receita e às vendas.

\subsection{Características do lugar e a coleta dos dados}

A pesquisa de campo de cunho qualitativa e descritiva, que, de acordo com Gil (2008), pode ser entendida como qualquer fenômeno descrito mediante a coleta de dados, usando técnicas com padronização, foi realizada na associação regularizada, a qual possui CNPJ, cujo nome é Carimbu, em novembro de 2019 na cidade de Sumé localizada no estado da Paraíba na região do Cariri. Essa associação é dos agricultores, extrativistas e artesãos do Cariri Paraibano, a qual foi legalizada a um ano em 30 de agosto com a finalidade de trabalhar com a cultura do Umbu e os derivados dele. O munícipio de Sumé é localizado a 265,6 Km via BR-230 e BR-412 da capital de João Pessoa conforme o Google Maps. A pesquisa contou com o uso de aparelhos celulares a fim de entrevistar, mediante a gravação de áudios, a técnica em agroindústria da UFCG/CDSA que coordena o projeto de Extensão Umbu do Cariri. Determinada associação onde está a unidade produtiva se localiza na Universidade Federal de Campina Grande, Campus de Sumé, no Laboratório de Tecnologia de Alimentos, onde é feito o beneficiamento e o processamento do Umbu. Diante disso, informações foram obtidas referentes ao procedimento operacional dos derivados do umbu, tendo também respostas relacionadas aos gastos do empreendimento quando se iniciou. Logo, foram-se obtidos todos os custos dos insumos e serviços, desde a colheita do produto agrícola em questão até ao produto agroindustrial final oriundo da cadeia de produção agroindustrial do umbu desde 2015 ao ano atual, 2019. Em adição, é válido salientar que foram feitas perguntas relacionadas aos maiores problemas referentes à colheita, demanda, transporte e à logística do umbu até ao laboratório onde se faz o beneficiamento do fruto e a produção dos derivados deste, assim como se foram questionados os entraves no que tange à distribuição das mercadorias e, por fim, teve conhecimento no que diz respeito como, aonde e quando ocorre o processo. Em adição, é importante salientar também 
que foi disponibilizado pela associação planilhas que mostram as vendas tanto do produto in natura quanto dos derivados.

O extrativismo ocorre em comunidades, o Caititu, assim como em assentamentos, o Mandacaru, municípios nos quais foram feitas as colheitas, não tendo, assim um local fixo para a produção do umbu. Além do mais, não há uma quantidade certa de umbuzeiros, no entanto, o que se sabe é que há uma estimativa pela qual informa que há 200 a 300 umbuzeiros nesse determinado assentamento, já que não há uma catalogação, isto é, um controle da quantidade da planta produtiva. Porém, de acordo com estudos de Silva, (2016) há aproximadamente 14 mil umbuzeiros em Sumé.

\subsection{Informações sobre a cooperativa}

O projeto de extensão Umbu do Cariri teve início em 2015 atendendo a comunidade rural e em 2018 passou a atender o Assentamento Mandacaru, comercializando apenas os frutos in natura e foi legalizada no ano de 2018 ao obter apoio institucional para realizar o beneficiamento em escala de bancada. Através da independência financeira obtida com o beneficiamento do umbu, visa oferecer autonomia as famílias das comunidades e empoderar mulheres em situação de violência doméstica, além de evitar o extrativismo predatório preocupando-se com a preservação das plantas existentes e replantio de mudas para futura utilização a nível industrial. Atualmente, conta com 17 sócios legalizados responsáveis pelo extrativismo nos assentamentos e, somando-se aos demais trabalhadores não regularizados membros do núcleo familiar, tem-se um número três vezes maior de pessoas envolvidas no processo da colheita que é realizada no período de safra e armazenada em forma de polpa para produzir os derivados, geleia e licor, ao longo do ano. Adotou o sistema de produção puxada e ainda não possui estimativas do lucro obtido por caixa beneficiada excetuando-se os custos, cada caixa comporta $25 \mathrm{~kg}$ de umbu, porém, não há estoque de polpa suficiente para atender a demanda de derivados. A proposta deste trabalho foi analisar o processo de colheita e obtenção de polpa nos anos de 2018 e 2019 e projetar um procedimento capaz de suprir uma maior demanda para os anos seguintes elevando os lucros de maneira significativa. Vale ressaltar que a associação recebe apoio institucional, portanto, para este estudo, não se considerou os custos atrelados a transporte e instalações.

\section{Resultados e Discussões}

\subsection{O procedimento produtivo dos derivados do umbu}


Em primeiro plano, é válido salientar que a colheita é realizada em comunidades e assentamentos onde se têm umbuzeiros.

Em segundo plano, após feita a colheita, as caixas que contêm os umbus são transportadas mediante um transporte gratuito disponibilizado pela própria universidade ao laboratório com o intuito de que os frutos possam ser beneficiados e processados. Os problemas encontrados em relação ao transporte e a logística foi que não se tem o conhecimento de geografia para que seja estabelecida a melhor rota da colheita à casa dos sócios, local de onde o carro da universidade transporta ao destino final, esse transporte é realizado com o uso de carros de boi, carroça de jumento ou até mesmo com moto, o que demanda muito tempo. Um dos maiores problemas encontrados no transporte é a questão dos custos no que se refere a comercialização do produto in natura às agroindústrias, porém, com o apoio de órgãos como a Universidade, Parque Tecnológico, PROCASE E PEASA, essa problemática foi amenizada.

Em terceiro plano, o produto processado é a Geleia, que após processada é colocada numa quantidade de $230 \mathrm{~g}$ em um pote de vidro. Além dela, tem-se outro produto agroindustrial final, o licor, o qual é colocado em garrafas de vidro de tamanho pequeno e médio que são reciclados em bares e locais afins, atuando com a reciclagem e há também a produção de umbuzada, mas não está no mercado por não apresentar dados referentes à validade. Com isso, esses produtos são advindos da polpa do umbu, a qual é o primeiro procedimento antes de produzir os produtos. No ano de 2019 durante os meses de safra e pela disponibilidade dos sócios, foi-se conseguido $92 \mathrm{Kg}$ de polpa de umbu para ser utilizada no processamento. Diante disso, são produzidos e transformado o produto in natura em polpa, o que envolve medidas de higienização e sanitização, assim essa polpa é armazenada em refrigerador, não tendo como armazenar o umbu por ele apresentar textura de moleza, o que não é viável ao processamento posterior.

Esses produtos agroindustriais, os derivados do umbu, começaram a ser fabricados e comercializados em março de 2019, porém nos anos anteriores, eram apenas comercializados os produtos in natura. Em adição, é importante perceber que há uma perda de aproximadamente $70 \%$ da produção de umbu in natura nas comunidades atendidas pelo projeto de extensão, por não ter onde armazenar e processar, ou seja, por não ter a estrutura adequada de receber todos os frutos para que sejam armazenados.

\subsection{Estudo de Caso}


O processo produtivo inicia-se com o extrativismo do umbu, mas ainda é um processo desordenado, não há rotina de trabalho apropriada para quantificar a capacidade de colheita por pessoa. Havendo demanda para os frutos in natura, a expedição é feita após a colheita, caso contrário, são levados para o local de beneficiamento, onde os frutos são higienizados e os processos de despolpamento, envase e congelamento são realizados em sequência, a fim de garantir a preservação das propriedades do fruto, tais como, cor, aroma e sabor, gerando estoque de polpas para serem utilizadas ao longo do ano na produção de geleias e licores após a safra.

Na figura 1, tem-se o fluxograma do processo produtivo adotado atualmente pela cooperativa:

Figura 1-Fluxograma atual do processo

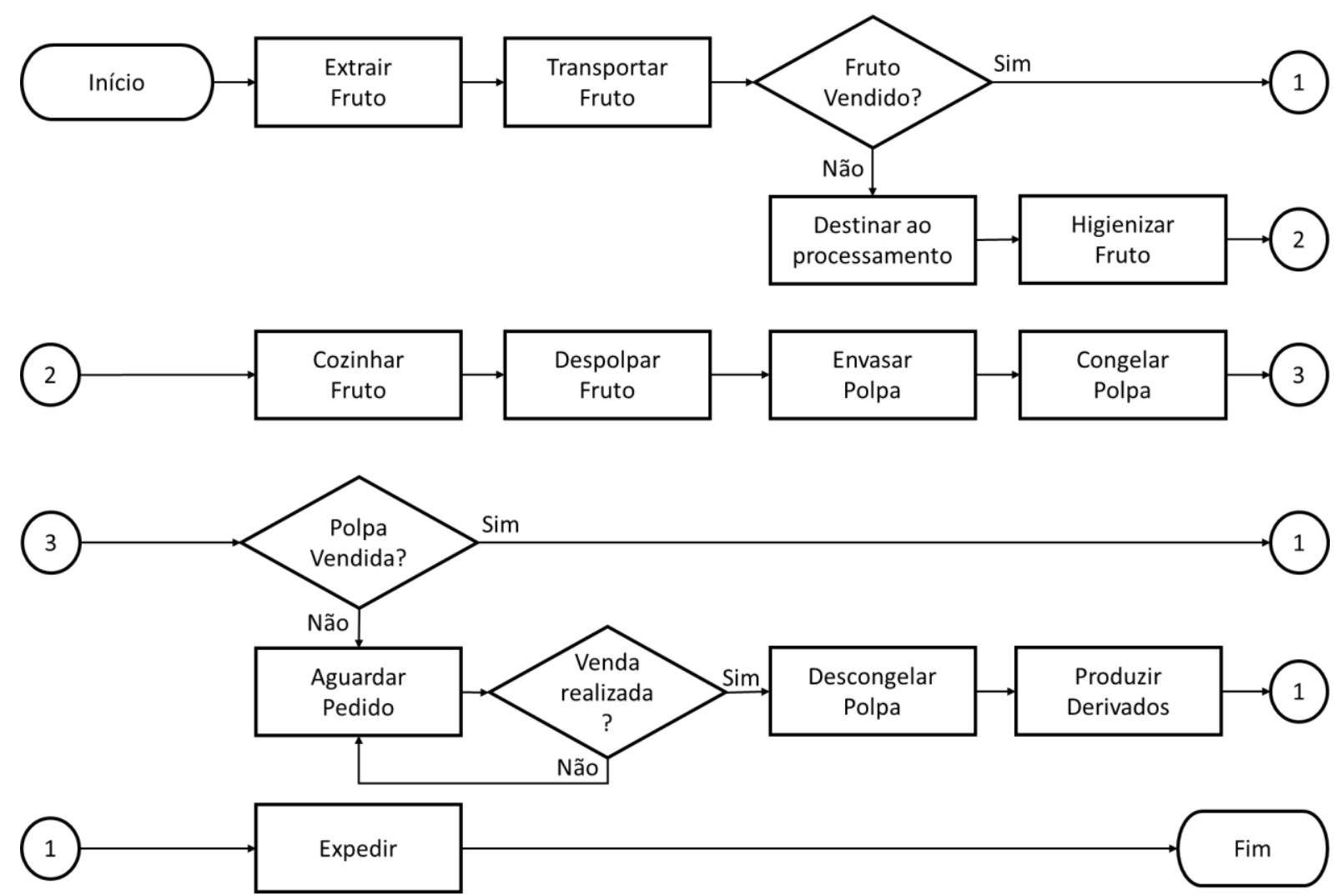

Fonte: Autoria Própria (2019)

Em 2018, primeiro ano de operações de beneficiamento, foi possível armazenar $27 \mathrm{~kg}$ de polpa no período da safra. Já no ano de 2019 foram armazenados $92 \mathrm{~kg}$ de polpa, representando aumento de, aproximadamente, $340 \%$ em relação a produção de polpa no ano anterior, porém, apesar de expressivo, esse aumento ainda não é capaz de suprir a alta demanda por derivados. Informações da associação mostram que o umbu possui cerca de $60 \%$ de rendimento de polpa, 
a partir desse dado, podemos analisar a produção média de polpa por dias úteis durante a safra em 2019, como mostra a tabela 1:

Tabela 1 - Dias úteis durante safra do umbu em 2019

\begin{tabular}{|c|c|}
\hline SAFRA 2019 & DIAS ÚTEIS \\
\hline Março & 20 \\
\hline Abril & 21 \\
\hline Maio & 22 \\
\hline Junho & 20 \\
\hline TOTAL & $\mathbf{8 3}$ \\
\hline
\end{tabular}

Fonte: Autoria Própria (2019)

Safra 2019 (83 dias úteis):

- $\quad 92 \mathrm{~kg}$ de polpa $=153,333 \mathrm{Kg}$ de $\mathrm{umbu}=6,13$ caixas

- $\quad$ Produção diária de polpa $=153,333 / 83=1,847 \mathrm{Kg} /$ dia

A tabela 2 mostra o histórico de produção de geleia do umbu a partir da polpa, o rendimento obtido, os custos e os lucros inerentes ao processo, com aproximadamente 3 horas trabalhadas por dia em que ocorreu produção: 
Tabela 2 - Custos da produção de geleia

\begin{tabular}{|ccccccc|}
\hline DIA & POLPA (Kg) & CUSTO (R\$) & POTES (230g) & POTES (180g) & VENDA (R\$) & LUCRO (R\$) \\
\hline 1 & 2,000 & 44,54 & 12 & 0 & 180,00 & 135,46 \\
2 & 2,710 & 79,79 & 2 & 21 & 282,00 & 202,21 \\
3 & 3,745 & 97,16 & 27 & 0 & 405,00 & 307,84 \\
4 & 2,870 & 80,87 & 23 & 0 & 345,00 & 264,13 \\
5 & 2,565 & 76,15 & 22 & 0 & 330,00 & 253,85 \\
6 & 2,820 & 79,03 & 6 & 17 & 294,00 & 214,97 \\
7 & 3,000 & 87,07 & 0 & 25 & 300,00 & 212,93 \\
8 & 4,125 & 116,88 & 34 & 1 & 522,00 & 405,12 \\
9 & 4,265 & 127,78 & 38 & 1 & 582,00 & 454,22 \\
10 & 1,000 & 58,25 & 19 & 0 & 285,00 & 226,75 \\
11 & 3,170 & 75,88 & 22 & 0 & 330,00 & 254,12 \\
12 & 3,000 & 109,25 & 21 & 0 & 315,00 & 205,75 \\
13 & 2,125 & 51,53 & 12 & 0 & 180,00 & 128,47 \\
14 & 2,970 & 110,52 & 22 & 1 & 342,00 & 231,48 \\
15 & 2,960 & 94,44 & 20 & 0 & 300,00 & 205,56 \\
16 & 2,940 & 103,06 & 0 & 25 & 300,00 & 196,94 \\
17 & 3,485 & 96,32 & 24 & 0 & 360,00 & 263,68 \\
18 & 3,965 & 82,69 & 28 & 1 & 408,00 & 325,31 \\
\hline TOTAL & $\mathbf{5 3 , 7 1 5}$ & $\mathbf{1 5 7 1 , 2 1}$ & $\mathbf{3 3 2}$ & $\mathbf{9 2}$ & $\mathbf{6 0 6 0 , 0 0}$ & $\mathbf{4 4 8 8 , 7 9}$ \\
\hline
\end{tabular}

Fonte: Autoria Própria (2019)

Os dados de custo e rendimento em potes apresentados na tabela fazem parte do controle de custos da associação, porém, o lucro estimado por quilograma ainda não era mensurado. A partir dessas informações, podemos concluir que até o início de novembro do ano de 2019:

- Foram 54h trabalhadas para produção de geleia;

- Processados 53,715 Kg de polpa;

- Rendimento de 424 potes de geleia;

- Custo da produção: $\mathrm{R} \$ 1.571,21$;

- Receita obtida: $\mathrm{R} \$ 6060,00$;

- Lucro: $\mathrm{R} \$ 4.488,79$.

Com esses dados, conclui-se que:

- $\quad$ Tempo para obter geleia a partir de $1 \mathrm{Kg}$ de polpa $=54 / 53,715=\sim 1 \mathrm{~h}$

- $\quad$ Custo por $\mathrm{Kg}$ de polpa processada $=\mathrm{R} \$ 1.571,21 / 53,715=\mathrm{R} \$ 29,25$ 
- $\quad$ Receita obtida por $\mathrm{Kg}$ de polpa $=\mathrm{R} \$ 4.488,79 / 53,715=83,56$

- $\quad$ Lucro por $\mathrm{Kg}$ de polpa $=83,56-29,25=\mathrm{R} \$ 54,31$

Esse total representa um lucro de $283,67 \%$.

Através destas informações, elaborou-se um plano de colheita e, consequentemente, obtenção de polpa para armazenar a quantidade máxima de matéria prima possível para produção de derivados e conseguir atender a demanda, aproveitando ao máximo sua capacidade de produção diária e aumentando os lucros.

\subsection{Propostas de melhorias}

De acordo com todas as informações coletadas, entende-se que os associados devem ser reorganizados em uma rotina, para atuarem na colheita durante a safra e no beneficiamento do umbu para tentar encontrar um equilíbrio entre oferta e demanda até obterem estrutura para processar em escala industrial.

Fazendo uma análise de dias e horas úteis ao trabalho para o ano de 2020, obtêm-se os seguintes dados:

Tabela 3 - Dias e horas úteis ao trabalho na safra 2020

\begin{tabular}{|c|c|c|}
\hline SAFRA 2020 & DIAS ÚTEIS & $\begin{array}{c}\text { HORAS DISPONÍVEIS } \\
\text { DE TRABALHO } \\
\text { (8h/dia) }\end{array}$ \\
\hline Março & 22 & 176 \\
\hline Abril & 20 & 160 \\
\hline Maio & 20 & 160 \\
\hline Junho & 22 & 176 \\
\hline TOTAL & $\mathbf{8 4}$ & $\mathbf{6 7 2}$ \\
\hline
\end{tabular}

Fonte: Autoria Própria (2019)

De acordo com a tabela 3, podemos estimar uma produção de acordo com as seguintes relações:

- $\quad 1 \mathrm{~h}$ trabalhada $=1 \mathrm{Kg}$ de polpa processado;

- Proporcionalmente, $672 \mathrm{~h}$ trabalhadas $=672 \mathrm{Kg}$ de polpa processados

- $672 \mathrm{~kg}$ de polpa $=60 \%$ do umbu in natura;

Logo, 1120kg (44,8 caixas) de umbu in natura são necessários para aproveitar o período de safra em 2020 com eficiência e armazenar polpa para produção ao longo do ano.

Portanto, utilizar o tempo disponível ao processamento é primordial para atender a demanda, aumentar a produção e, consequentemente, lucros. Analisando todas as propostas, percebe-se que a associação tem grande potencial de crescimento e com as mudanças sugeridas, o lucro 
anual pode chegar a até $\mathrm{R} \$ 56.152,32$. Diante disso, é válido salientar que se desconsideram os custos inerentes ao transporte, às instalações, à água e à energia elétrica nesses cálculos, uma vez que a universidade colabora com a associação em questão.

\section{Considerações Finais}

No início deste trabalho, foram catalogados alguns objetivos pertinentes ao crescimento da Associação em questão, tais como a compreensão dos processos por meio do mapeamento do fluxo, o melhoramento do gerenciamento de custos, a identificação dos gargalos do processo, o aumento da produtividade e consequentemente a elevação dos lucros potenciais da Cadeia Produtiva. Analisou-se uma série de fatores que impossibilitavam esta expansão como a falta de um planejamento eficaz para a armazenagem da fruta in natura que resultava no não suprimento da demanda, a baixa produtividade proveniente da inexistência de uma rotina de trabalho eficiente e a não mensuração dos lucros alcançados pelas vendas dos produtos, sendo os fatores principais. Com a implementação de ferramentas da Gestão da Produção e o Mapeamento de Processos foi possível elaborar e propor melhorias na organização produtiva visando a alavancagem do potencial que a Associação Carimbu possui.

O plano de melhorias está voltado à reorganização dos associados para que estes possuam uma rotina de trabalho de 8 horas diárias nos dias úteis durante a safra para que se alcance um equilíbrio entre a oferta e a demanda com a finalidade de que a empresa esteja estruturada para atingir futuramente a produção em escala industrial e por fim o levantamento da previsão de demanda para a safra de 2020, já com os dados em consonância com as mudanças que deverão ser aplicadas para que a Associação Carimbu obtenha o seu funcionamento em capacidade plena. Com essas mudanças o lucro anual terá um crescimento extremamente significativo de $\mathrm{R} \$ 4.488,79$ para $\mathrm{R} \$ 56.152,32$. Após a conclusão do trabalho, as expectativas do grupo estão consideradas alcançadas com sucesso, visto que conseguimos elaborar um plano de melhoria para a organização produtiva supracitada, reiterando a importância da aplicação dos conhecimentos técnicos da Engenharia de Produção nas empresas da região, sendo o Cariri Paraibano um polo promissor para o Agronegócio em escala regional.

\section{REFERÊNCIAS}

ARAUJO, Luis César G. de. Organização, sistemas e métodos: e as tecnologias de gestão organizacional, benchmarking, empowerment, gestão pela qualidade total, reengenharia. 5. Ed. São Paulo: Atlas, 2011. (b). 
BARBROW, S.; HARTLINE, M. Process mapping as organizational assessment in academic Librarie.

Performance Measurement and Metrics, v. 16, n. 1, p. 34-47, 2015

BELKE, R.; BERTÓ D. J. Gestão de custos. São Paulo: Saraiva, 2005.

CARVALHO, M. M.; et al. Gestão da qualidade: teoria e casos. $6^{\text {a }}$ ed. Rio de Janeiro: Elsevier, 2005.

CASTRO, N.R. PRODUTIVIDADE DO TRABALHO CRESCE MAIS NO AGRONEGÓCIO QUE NO

BRASIL E IMPULSIONA PIB DO SETOR. Centro de Estudos Avançados em Economia Aplicada (CEPEA),c2019.<https://www.cepea.esalq.usp.br/br/opiniao-cepea/produtividade-do-trabalho-cresce-mais-noagronegocio-que-no-brasil-e-impulsiona-pib-do-setor.aspx>.Acesso em: 10 de nov. de 2019.

CHINELATO FILHO, João. Arte de organizar para informatizar. Rio de Janeiro: LTC, 1993.

CURY, Antonio. Organização e Métodos: Uma Visão Holística. 8 Ed. rev. e ampl. 5. reimpr. São Paulo: Atlas, 2010.

DUTRA, R. G. Custos: Uma abordagem prática. 4 ed. São Paulo: Atlas, 1995.

GIL, Antonio Carlos. Métodos e técnicas de pesquisa social. 6. ed. Ediitora Atlas SA, 2008.

GAMA, D.C et. al. O Cambuí (Myrciaria tenella (DC.) O. BERG; MYRTACEAE): extrativismo e geração de renda em Ribeira do Pombal-Bahia. Revista Brasileira de Agroecologia, v. 12, n. 1, 2017.

MAPA. Associativismo rural. Ministério da Agricultura, Pecuária e Abastecimento, 01 de dez. de 2016; $<$ http://www.agricultura.gov.br/assuntos/cooperativismo-associativismo/associativismo-rural $>$. Acesso em: $11 \mathrm{de}$ nov. de 2019.

MARETH, T.; ALVES, T. W.; BORBA, G. S. Mapeamento de processos e simulação como procedimentos de apoio à gestão de custos: uma aplicação para o processo de registros e matrículas da universidade de Cruz Alta. In: Congresso USP, IX, São Paulo. Anais, 2009.

MÁSCULO,F.S. Um panorama da Engenharia de produção. Associação Brasileira de Engenharia de produção (ABEPRO),c2006.< http://www.abepro.org.br/interna.asp?ss=1\&c=924>. Acesso em: $11 \mathrm{de}$ nov. de 2019.

SOUZA, G. C. Extrativismo em área de reserva da Biosfera da mata atlântica no rio 53 grande do sul - Um estudo Etnobiológico em Maquiné. 2003. 202p. Tese (Doutorado): Botânica área de concentração: Etnobotânica, Universidade Federal do Rio Grande do Sul. Porto Alegre, 2003.

OLIVEIRA, R. P. D. Sistemas, organização e métodos. São Paulo: Atlas, 2013.

OROFINO, Antônio Carlos. Processos com resultados: a busca da melhoria continuada. Rio de Janeiro: LTC, 2009. 
SILVA, D. V. DA. OS IMBUZEIROS DE SUMÉ: construído perspectivas para o extrativismo sustentável. n. June, 2016.

ZAHAIKEVITCH, E. V. Identificação dos principais atributos dos produtos para formação do preço de venda: um estudo de caso nas micro e pequenas empresas da região de Irati - PR. 2012. 67 f. Trabalho de Conclusão de Curso (Especialização em Engenharia da Produção) - Universidade Tecnológica Federal do Paraná. Ponta Grossa, 2012 